RELACult - Revista Latino-Americana de Estudos em Cultura e Sociedade

Revista Latinoamericana de Estudios en Cultura y Sociedad | Latin American Journal of Studies in Culture and Society

V. 02, Ed. Especial, dezembro, 2016, p. 275-282| periodicos.claec.org e-ISSN 2016/Atual: 2525-7870 | e-ISSN 2015/2016: 2447-018X

\title{
As mulheres e a construção da Colônia de Pescadoras Z25 em Jaguarão/RS - 2005
}

Las mujeres e la construción de la Colônia de Pescadoras Z25 en Jaguarão/RS - 2005

Women and the construction of the Cologne Fisherwomen Z25 in Jaguarão / RS - 2005

Kênya Jessyca Martins de Paiva ${ }^{1}$

\section{Resumo}

A proposta deste trabalho é discutir sobre a trajetória de uma das mulheres que fundou, junto de outras pessoas, a Colônia de Pescadoras Z25 em Jaguarão (2005). A entrevistada se chama Roselein Dias (62 anos), é presidenta da Colônia de pescadoras, nasceu e se criou numa família de pescadores e por isso, sempre esteve envolvida com as questões ligadas a sua classe. Rosa, como é chamada pela maioria dos moradores da Vila de Pescadores, é reconhecida como uma forte liderança entre as pescadoras e os pescadores. Para conhecer sua história foi utilizada a metodologia da História Oral, onde foram realizadas entrevistas gravadas com duração em média de 60 minutos, que posteriormente, foram transcritas pela pesquisadora. As perguntas foram orientadas para saber os motivos que levaram as mulheres naquele período a fundar a Colônia, qual é a importância dela atualmente na comunidade pesqueira de Jaguarão, quais foram os benefícios e possíveis dificuldades incluídas nesse processo de organização, etc.

Palavras-chave: Mulheres; pescadoras; História Oral; Jaguarão; Colônia Z25.

\begin{abstract}
The purpose of this paper is to discuss the trajectory of one of the women who founded, along with others, the Cologne Fisherwomen Z25 in Jaguarão (2005). The interviewee is called Roselein Days (62 years), is president of the Colony of fisherwomen, he was born and raised in a family of fishermen and therefore has always been involved with issues related to their class. Rosa, as it is called by most residents of Fisherman's Village, is recognized as a strong leadership among fisherwomen and fishermen. To know its history was used the methodology of Oral History, which were conducted taped interviews with average duration of 60 minutes each, which were later transcribed by the researcher. The questions were oriented to know the reasons women at that time to found the colony, which is the importance now of it in the fishing community of Jaguarão, what were the benefits and difficulties included in this process of organization, such as the fishermen cooperate to the operations of the Cologne, among others.
\end{abstract}

Keywords: Women; fisherwomen; Oral History; Jaguarão; Cologne Z25.

\section{Resumen}

\footnotetext{
${ }^{1}$ Mestranda em História pela Universidade do Estado de Santa Catarina - UDESC, Florianópolis, Santa Catarina, Brasil. kenya.paiva@hotmail.com
} 
El propósito de este trabajo es analizar la trayectoria de una de las mujeres que fundaron, junto con otros, la Colonia Fisherwomen Z25 en Yaguarón (2005). El entrevistado se llama Roselein Días (62 años), es presidente de la Colonia de pescadoras, que nació y se crió en una familia de pescadores y, por tanto, siempre ha estado involucrado en asuntos relacionados con su clase. Rosa, como se le llama por la mayoría de los residentes de un pueblo de pescadores, es reconocido como un fuerte liderazgo entre las pescadoras y pescadores. Para conocer su historia se utilizó la metodología de la historia oral, que se llevaron a cabo entrevistas grabadas con una duración promedio de 60 minutos cada uno, que luego fueron transcritas por el investigador. Las preguntas estaban orientadas a conocer las razones por las mujeres en ese momento para fundar la colonia, que es la importancia ahora de la misma en la comunidad pesquera de Yaguarón, lo que fueron los beneficios y dificultades incluidas en este proceso de organización, como los pescadores cooperan para las operaciones de la Colonia, entre otros.

Palabras Clave: Mujeres; pescadoras; Historia Oral; Yaguarón; Colonia Z25.

\section{INTRODUÇÃO}

A pesca está inserida no setor primário da economia, fazendo parte do conjunto de atividades econômicas que extraem e/ou produzem matéria-prima diretamente da natureza, que podem ser consumidos enquanto tal ou serem transformados em mercadorias. As atividades importantes neste setor incluem agricultura, a pesca, a pecuária e a mineração em geral, e é chamada por esse nome por ter sido as primeiras a serem desenvolvidas pela humanidade, sendo a prática constitutiva das civilizações. Segundo a nomenclatura econômica, este setor é composto por seis atividades econômicas: agricultura, pecuária, extrativismo vegetal, caça, mineração, extração de recursos não-renováveis e a pesca.

As pessoas que trabalham com a pesca transitam no mundo contemporâneo forjando formas de resistências e mecanismos para conquista de seus direitos como trabalhadoras e trabalhadores. A atividade pesqueira teve sua origem ligada aos primeiros grupos humanos a habitar o Brasil. A herança deixada por diversas nações indígenas na cultura da pesca também pode ser observada a partir dos arranjos artesanais, como redes, armadilhas, cestarias produzidas e utilizadas ainda hoje por grupos indígenas e não indígenas (CARDOSO, 2009, 1). A pesca que inicialmente tinha como destino suprir o consumo alimentar, com o passar dos anos foi assumindo novas características. Em 1960, com o surgimento da pesca extrativista industrial, passou a adotar técnicas e tecnologias de trabalho que resultariam na comercialização em larga escala da produção. Por outro lado, a pesca artesanal continua sendo responsável pela maior parte da produção pesqueira no Brasil e responsável pela sobrevivência de milhares de brasileiras e brasileiros das camadas populares, além de permitir o desenvolvimento econômico de forma autônoma, como é o caso da comunidade ribeirinha do Município de Jaguarão.

As trabalhadoras e os trabalhadores da pesca passaram a se organizar, ao longo de décadas, para conquistar direitos importantes para a categoria. Como resultado, temos 

e-ISSN 2016/Atual: 2525-7870 | e-ISSN 2015/2016: 2447-018X

sindicatos, associações e Colônias de pescadores por todo o Brasil. As primeiras colônias de pescadores do Brasil foram fundadas a partir de 1919, implementadas pela Marinha.

Jaguarão, Município situado ao sul do Rio Grande do Sul com 30 mil habilitantes, desde 2005 possui uma Colônia de Pescadoras. De acordo com dados retirados do livro "Pescadores da Lagoa Mirim. Etnoecologia e Resiliência", na cidade há cerca de 75 pescadores, organizados em dois seguimentos políticos, a Colônia de Pescadoras Z-25 que conta com mulheres e homens, e o Sindicato de Pescadores composto por apenas homens e há também os pescadores que não se declaram de nenhuma entidade. (PIEVE; KUBO; COELHO, 2009, 90).

A proposta deste trabalho é discutir sobre a trajetória de uma das mulheres que fundou, junto de outras pessoas, a Colônia de Pescadoras Z25 em Jaguarão (2005). A entrevistada se chama Roselein Dias (62 anos), é presidenta da Colônia de pescadoras, nasceu e se criou numa família de pescadores e por isso, sempre esteve envolvida com as questões ligadas a sua classe.

Rosa, como é chamada pela maioria dos moradores da Vila de Pescadores, é reconhecida como uma forte liderança entre as pescadoras e os pescadores. Para conhecer sua história foi utilizada a metodologia da História Oral, que de acordo com Meihy:

\footnotetext{
História oral é um conjunto de procedimentos que se iniciam com a elaboração de um projeto e continuam com a definição de um grupo de pessoas (ou colônia) a serem entrevistadas, com o planejamento da condução das gravações, com a transcrição, com a conferência do depoimento, com a autorização para o uso, arquivamento e, sempre que possível, com a publicação dos resultados que devem, em primeiro lugar, voltar ao grupo que gerou as entrevistas (MEIHY, 1996: 15).
}

Dessa forma, foram realizadas entrevistas gravadas com duração em média de 60 minutos, que posteriormente, foram transcritas pela pesquisadora e autorizadas a partir de um documento assinado pela pescadora. As perguntas foram orientadas para saber os motivos que levaram as mulheres naquele período a fundar a Colônia, qual é a importância dela atualmente na comunidade pesqueira de Jaguarão, quais foram os benefícios e dificuldades incluídas nesse processo de organização, entre outras. A pesquisa ainda esta em sua fase inicial, mas como resultados principais no momento temos a criação de uma fonte oral/escrita e a inserção de relatos de uma pescadora sobre o seu cotidiano que nos servem para pensar sobre a História da pesca na cidade de Jaguarão. 

e-ISSN 2016/Atual: 2525-7870 | e-ISSN 2015/2016: 2447-018X

\section{Conhecendo um pouco sobre a Dona Rosa - Presidenta da Colônia de Pescadoras}

\section{Z 25.}

Conheci a entrevistada a partir do auxílio de uma moradora da região da "Vila dos Pescadores", chamada Carmem Machado. Apesar de morar próxima da Vila, Carmem não é pescadora, ela cursa Pedagogia na Universidade Federal do Pampa e há algum tempo atrás havia feito um trabalho sobre as mulheres pescadoras. Por isso conhece boa parte das pescadoras e elas mostraram depositar bastante confiança nela. Roselein Termezana é a liderança principal reconhecida pelas próprias pescadoras, é uma senhora que estava alegre, voz mansa, calma, mostrou ser uma mulher muito aguerrida, voltada para o cuidado das netas e ocupada com as questões da Colônia de Pescadoras Z 25.

Rosa, como é conhecida, conta aspectos do período em que seu pai era pescador, de acordo com ela "a pesca era bem diferenciada hoje se pesca com redes, mas antes não tinha gelo, o peixe era salgado e eram pescados com anzol (...) depois veio as redes com cordão”. Rosa estudou no Uruguay, lá ela tinha "aula de canto, (...) cantava no Coral Municipal. A gente tinha aula de dança, aula de piano, de canto, tinha aula de tudo. E (...) a gente fazia olimpíadas nos colégios uma vez no ano". Sua mãe e pai eram uruguaios, por isso estudou na infância e juventude lá, no entanto, utilizou a Educação de Jovens e Adulto e o Exame Nacional do Ensino Médio -ENEM para concluir o Ensino Médio aqui no Brasil.

Quando questionei sobre quando iniciou os trabalhos como pescadora, ela responde que "eu acho que desde guria, eu já pescava com meu pai, quando eu casei, eu que levei meu marido a pescar", antes disso seu esposo era comerciante e jogador de futebol, mas foi nas águas que encontrou a sua vocação. É casada há 47 anos com seu companheiro, hoje ela com 62 anos e ele com 71 anos. Ela nos conta que foi com muita dificuldade que convenceu seu marido a se aposentar e a vender seus equipamentos de pesca e o barco, mas ressalta que só conseguiu convencê-lo porque a venda foi para um dos netos, ou seja, ia permanecer em família e a vista de seu companheiro.

Rosa relata que na época em que seu pai pescava, sua mãe era do lar e "ajudava" nas tarefas do marido. Embora saibamos que essa ajuda provavelmente se constituía em um elemento fundamental para o preparo do peixe que seria posteriormente comercializado, arrumação de rede, limpeza e outras atividades importantes, naquele período acredito que não havia a consolidação da identidade da mulher como pescadora - independente dela sair para as águas junto do companheiro - por isso, a pescadora afirma que sua mãe era tão somente do lar. No Código de Pesca de 1967 não houve reconhecimento das mulheres como pescadoras, 
somente com a Lei $\mathrm{n}^{\circ} 6.807$, de 1980, houve registro para mulheres na pesca artesanal, mas ainda assim, era voltada para as que trabalhavam diretamente nas águas.

Rosa começa seu dia de trabalho bem cedo:

Meu dia começa às $6 \mathrm{~h}$ da manhã, $6 \mathrm{~h}$ e $30 \mathrm{~min}$ eu saio de casa, chego a $1 \mathrm{~h}$. (...) se eu tenho horário de banco, alguma coisa pra fazer até as $15 \mathrm{~h}$, das $16 \mathrm{~h}$ até as $18 \mathrm{~h}$ eu atendo a Colônia e nesse meio tempo tenho que ter tempo de ir lá dar banho na bisneta.

E foi meio a essa rotina agitada que ela me recebeu em sua casa, que também é a sede da Colônia de Pescadoras. A entrevistada ressalta que para as mulheres a pesca é muito mais sacrificada do que para os homens, por causa do cuidado das crianças, do frio, do trabalho que é dar conta de tudo ao mesmo tempo. Ela criou todos os filhos e filhas nas águas e todos seguiram a profissão: "Eu tenho três filhos pescadores e uma filha. E tenho dois adotivos, que são pescadores, e agora um neto, que seguiu a geração da família”.

$\mathrm{O}$ envolvimento das mulheres pescadoras com o rio foi outro aspecto que merece ser considerado, a maioria das mulheres nas quais entrevistei, reagem como Rosa, para ela "água é vida, em todos os sentidos, a gente nasce da água, porque nasce numa bolsa d'água, a agua é vida. Quando dá uma enchente todo mundo fica apavorada, eu fico feliz da vida e dou risada (risos)". É recorrente encontrar pesquisas com relatos semelhantes a esse quando se trata do rio, afinal as trajetórias de vida dessas mulheres se constituem com experiências voltadas entorno do Rio Jaguarão, já que suas moradias são próximas, a de Rosa mesmo fica em frente. Isso faz com que elas tenham um outro olhar e um sentimento próprio de quem realiza o trabalho, vive e vê crescer sua família, sempre nas águas.

\section{2. "Essa colônia (...) foi criada com muito suor, com lágrimas e garra!": Sobre a criação da Colônia de Pescadoras Z 25.}

A criação das Colônias de pescadores ocorrem desde 1919, quando, de acordo com a pesquisadora Catia Antonia da Silva, a Marinha Brasileira cria as Zonas de Pesca, que são "núcleos de pescadores levando em conta quantidade e distância em todas as sedes mapeada que já tinham a tradição de ser chamadas de Colônia de pescadores”. (SILVA, 2014, p. 3). As colônias são entidades de classe que servem para orientar as e os pescadores, assim como, prestar os serviços necessários para garantir que os seus direitos sejam cumpridos.

O trabalho das pescadoras e dos pescadores para a criação de uma Colônia em Jaguarão foi intensa, Rosa que é presidenta da Colônia, em seu depoimento nos narra como se deu esse processo iniciado a partir de um encontro de mulheres em Brasília: 


\begin{abstract}
Essa colônia, eu sempre digo assim, ela foi criada com muito suor, com lágrimas e garra! Eu fui numa Conferência de mulheres em Brasília, na primeira Conferência da Mulher, e nós aqui éramos ligadas a um sindicato e somos ainda, a gente já não é mais né, mas tem pescadores atrelados a mais de trinta anos nele (...). A maioria das pessoas não tinha documentação (...). E as mulheres eram discriminadas (...).
\end{abstract}

Por não serem consideradas como trabalhadoras da pesca, enfrentavam dificuldades como nos traz a entrevistada: "elas não conseguiam se aposentar, elas não conseguiam ter um salário maternidade, elas não conseguiam se adoecesse ter um benefício, não conseguiam nada e em Brasília a gente levou isso aí, nessa conferência”. Nesse sentido, em 2005, Rosa juntamente de outras pescadoras e pescadores criam a Colônia de Pescadoras Z 25 em Jaguarão e ainda percorrem outras diversas cidades do Rio Grande do Sul na intenção de formar novas Colônias.

A pescadora nos conta um pouco sobre essa entidade: "As colônias de pesca foram as primeiras colônias criadas no Brasil. Criadas pela Marinha (...) e nós viemos e criamos (...) e estamos com a Colônia até hoje". Além da Colônia de Pescadoras, posteriormente foi necessária a criação da Associação de Pescadoras e Pescadores de Jaguarão, pois de acordo com Rosa, que nessa última entidade desempenha a função de secretária, "nós criamos a associação por que a Colônia não pode comercializar e aí criamos a Associação para poder comercializar".

Rosa também nos relata sobre a importância da união das mulheres para a consolidação e manutenção da Colônia de Pescadoras e como essa construção é uma grande vitória para as trabalhadoras e trabalhadores da pesca em Jaguarão. Uma das conquistas que ela cita durante a entrevista foi a aposentadoria de quatro pescadoras: "desde que a gente criou essa Colônia é só vitória pra gente, por que a mulher pode ter dignidade, ter a sua documentação e hoje eu tenho quatro mulheres aposentadas. Quatro mulheres já!’.

A antropóloga Rose Gerber, representante da equipe da Gerência de Extensão Rural e Pesqueira (GERP) da Empresa de Pesquisa Agropecuária e Extensão Rural de Santa Catarina (EPAGRI), em seu livro "Mulheres e o Mar: Pescadoras embarcadas no litoral de Santa Catarina, sul do Brasil" (2015) escreve sobre a rotina de vinte e duas pescadoras catarinenses e as suas dificuldades frente ao machismo, tanto dos colegas de profissão como dos agentes da esfera pública. Gerber no seu $5^{\circ}$ capítulo (pág. 203-258), em que trata da relação das pescadoras com o Estado, aponta que o mercado e as instituições públicas enxergam e tratam as mulheres como auxiliares dos homens no trabalho pesqueiro, isto é, muitas vezes elas são 
vistas somente como ajudantes e não como protagonistas. Através da entrevista com a pescadora e liderança, Rosa, é possível desnaturalizar essa ideia de que as mulheres só ajudam, pois em Jaguarão foram elas quem criaram a Colônia de Pescadoras, elas estão inseridas no processo de trabalho, elas estão afrente das discussões sobre a pesca, elas informam os colegas e elas também cobram as suas demandas junto aos setores públicos.

Através desses relatos percebemos como é dificultoso para as mulheres, dentro desse sistema patriarcal e capitalista, conquistarem sua legitimidade, assim como, seus direitos previdenciários e trabalhistas. Foi preciso muita atuação política, construção de espaços e empoderamento para que elas pudessem ter alguns de seus direitos garantidos e suas demandas específicas serem consideradas como importantes. As mulheres, dentro do ramo da pesca, como vimos ainda lutam pelo devido reconhecimento, pois apesar delas também fazerem parte do processo de produção pesqueira do país, não são tratadas com a mesma legitimidade oferecida aos homens pescadores.

\section{CONSIDERAÇÕES FINAIS}

A pesquisa esta em sua fase inicial, mas como primeiros resultados foi possível perceber a trajetória de uma importante liderança das e dos pescadores, assim como seus espaços de lutas, dentro e fora da cidade. É interessante identificar o protagonismo da nossa entrevistada, que mesmo permeando um mundo masculino como é o da pesca, consegue forjar sua atuação como mulher e como pescadora, organizando a comunidade pesqueira para construção de espaços de representação da categoria. Através da organização das pescadoras, a discriminação machista dentro da pesca esta sendo colocada em debate e isso favorece a luta pela visibilidade das demandas específicas para as mulheres no cenário das políticas públicas.

A História Oral, ferramenta utilizada para buscar as narrativas, cumpre nesse momento um papel fundamental que é de reconhecer e introduzir vozes silenciadas e longes do campo acadêmico, como é o caso de Rosa.

\section{FONTE HISTÓRICA}

DIAS, Roselen Termezama. Entrevista I. [agosto 2016]. Entrevistadora: K. Martins. Jaguarão, 2016. 1 arquivo .mp3 (60 min.).

\section{REFERÊNCIAS}

CARDOSO, E. S. Trabalho e Pesca: Apontamentos para a Investigação. Revista Pegada Eletrônica, Presidente Prudente, vol. 10, n. 2, 31 dezembro 2009. 

e-ISSN 2016/Atual: 2525-7870 | e-ISSN 2015/2016: 2447-018X

DIEGUES, A. C.; ARRUDA, R. S. V. Saberes Tradicionais e Biodiversidade no Brasil. Brasília: Ministério do Meio Ambiente; São Paulo: USP, 2001.

GARCEZ, D. M. Diagnóstico das comunidades de pescadores artesanais do Rio Grande do Sul, 35p. Relatório consultoria, SAA-RS/IICA, Porto Alegre, 2001.

GERBER, Rose Mary. Mulheres e o mar: Pescadoras embarcadas no litoral de Santa Catarina, sul do Brasil. Editora UFSC. 2015

MALDONADO, S. C.. Pescadores do mar. São Paulo: Ática, 1986.

MEIHY, José Carlos Sebe Bom. Manual de História Oral. São Paulo: Loyola, 1996.

PIEVE, Stella Maris Nunes; KUBO, Rumi Regina; COELHO, Gabriela de Souza. Pescadores da Lagoa Mirim. Etnoecologia e Resiliência. MDA. Brasília, 2009.

PASQUOTTO, Vinicius Frizzo. Pesca artesanal no Rio Grande do Sul: os pescadores de São Lourenço do Sul e suas estratégias de reprodução social. Porto Alegre: UFRGS, 2005.

SILVA, Catia Antonia da. Pescadores artesanais e território: possibilidades e limites ao acesso aos direitos sociais e políticas publicas. In: VII Congresso Brasileiro de Geógrafos. Vitória/ES 2014, p. 1-12. Anais ISBN 9788598539-041. Disponível em: http://www.cbg2014.agb.org.br/resources/anais/1/1404393107_ARQUIVO_textoCBGPROE XTcatia,naraeRhanna_final.pdf. Acessado dia 10 de setembro de 2016.

SOIHET, Rachel; PEDRO, Joana Maria. A emergência da pesquisa da história das mulheres e das relações de gênero. Rev. Bras. Hist. 2007, vol.27, n. 54, pp. 281-300. http://dx.doi.org/10.1590/S0102-01882007000200015. 